\title{
PENGARUH KUALITAS PELAYANAN JASA BANK TERHADAP PENINGKATAN JUMLAH KEUNTUNGAN BANK SWASTA "XYZ"CABANG PEKANBARU
}

\author{
Syahdanur \\ Gatot Wijayanto
}

\begin{abstract}
ABSTRAK
Penelitian ini bertujuan untuk menganalisis pengaruh faktor kualitas pelayanan jasa bank yang terdiri dari faktor Tangible, Reliablity, Responsiveness, Assurance, dan Emphaty terhadap peningkatan jumlah keuntungan Bank Swasta "XYZ" Cabang Pekanbaru, baik secara simultan maupun parsial dan untuk mengetahui faktor kualitas pelayanan jasa bank yang mempunyai pengaruh paling dominan terhadap peningkatan jumlah keuntungan Bank Swasta "XYZ" Cabang Pekanbaru. Dengan mengambil sampel sebanyak 100 responden dengan rumus Slovin dari keseluruhan nasabah yang menabung di Bank Swasta "XYZ" Cabang Pekanbaru sebanyak 25.422 orang sebagai populasinya dan analisis datanya menggunakan Analisis Jalur (Path Analisis).

Dari hasil pengujian statistik menunjukkan bahwa aspek dimensi Responsiveness yang merupakan nilai pelayanan jasa bank berpengaruh relatif besar terhadap peningkatan jumlah keuntungan Bank Swasta "XYZ" Cabang Pekanbaru. Agar kualitas dan nilai palayanan Bank Swasta "XYZ" Cabang Pekanbaru mampu memberikan konstribusi yang lebih tinggi lagi terhadap peningkatan jumlah keuntungan Bank Swasta "XYZ" Cabang Pekanbaru, maka selayaknya Bank Swasta "XYZ" Cabang Pekanbaru mempertimbangkan; masalah perluasan jaringan dan prasarana pendukung, penyempurnaan sistim dan prosedur yang didukung oleh sistim komputerisasi, meningkatkan kemudahan dalam proses pembukaan, penyetoran dan penarikan dana, adanya kepedulian terhadap para nasabah agar tercipta brand loyalty. Di samping itu, agar nilai kualitas pelayanan yang dilakukan oleh Bank Swasta "XYZ" Cabang Pekanbaru tetap baik sehingga dapat meningkatkan keuntungan bank, maka perlunya meningkatkan keindahan inrterior dan eksterior yang khas tempat melakukan pelayanan bagi para nasabah.
\end{abstract}

Key Words: Kualitas Pelayanan, Jasa Bank, Jumlah Keuntungan Bank

\section{PENDAHULUAN}

Dalam usaha memacu perkembangan perekonomian di Indonesia, fungsi dan peranan jasa perbankan dewas ini semakin menduduki tempat terpenting. Jasa perbankan ini merupakan penompang hampir seluruh program dan kegiatan pembangunan ekonomi, industri, perdagangan dan dunia usaha maupun jasa-jasa lainnya.

Dalam situasi perekonomian sekarang ini hubungan antara bank dan masyarakat sulit untuk dapat dipisahkan. 
Pihak perbankan membutuhkan dana dari masyarakat sebagai salah satu modalnya untuk menyalurkan kredit. Sedangkan masyarakat sangat membutuhkan bank untuk mendapatkan berbagai macam jasa-jasa yang diberikan oleh pihak perbankan. Apalagi bagi masyarakat moderen yang sangat membutuhkan pelayanan jasa bank yang cepat dan tepat. Oleh karena itu dunia perbankan dituntut untuk memenuhi kebutuhan dan keinginan nasabah yang syarat akan palayanan jasa-jasa bank yang dapat memuaskan nasabahnya ataupun masyarakat luas pada umumnya. Dimana dengan kualitas dan nilai pelayanan yang dapat memuaskan nantinya akan dapat memberikan image yang positif pada setiap bank sebagai mitra masyarakat yang terampil dan terpecaya.

Agar masyarakat mau menyimpan uangnya di bank, maka pihak perbankan memberikan rangsangan berupa balas jasa dari suatu nilai pelayanan yang akan diberikan kepada si penyimpan. Balas jasa tersebut dapat berupa bunga, bagi hasil, hadiah, pelayanan atau balasa jasa lainnya. Semakin tinggi balas jasa yang diberikan, akan menambah minat masyarakat untuk menyimpan uangnya. Oleh sebab itu pihak perbankan harus memberikan berbagai rangsangan dan kepercayaan sehingga masyarakat berminat untuk menananmkan dananya.

Bank Swasta "XYZ" Cabang Pekanbaru sebagai perusahaan milik pemerintah daerah yang melakukan usaha perbankan guna menunjang perekonomian di daerah dengan menghimpun dana dari masyarakat sebanyak mungkin untuk kemudian menyalurkannya pada dunia usaha yang ada baik individu maupun kelompok yang ada di daerah Riau dan kota Pekanbaru pada khususnya. Dalam pelayanan jasa bank untuk memuaskan para nasabahnya memerlukan suatu strategi pemasaran guna memenangkan persaingan. Dimana pelayanan yang dirasakan oleh konsumen bukan sekedar untuk memenuhi kebutuhan dan keinginan nasabah, akan tetapi sudah mencapai tahap pemenuhan harapan dalam menyimpan dan meminjam uang.

Jika diamati secara langsung maupun informasi dari berbagai kalangan, saat ini Bank Swasta "XYZ" Cabang Pekanbaru merupakan salah satu pilihan yang diminati oleh pengguna jasa pelayanan bank. Mereka menyatakan kepuasannya terhadap nilainilai jasa pelayanan yang diberikan. Hal ini tentu sangat berdampak pisitif bagi kelangsungan hidup organisasi perusahaan. Pimpinan Bank Swasta "XYZ" Cabang Pekanbaru harus mengetahui hal-hal apa saja yang dianggap penting oleh para pengguna jasa pelayanan perbankan khususnya dalam meningkatkan jumlah keuntungan bank agar tercapai suatu tingkat kinerja (performance) yang optimal bagi pemuasan nasabah.

Kepuasan para nasabah amatlah ditentukan oleh kualitas dan nilai kegunaan dari barang/jasa yang dikehendaki oleh nasabah, sehinga jaminan kualitas dan nilai menjadi prioritas utama setiap perusahaan, termasuk bagi perusahaan non-laba, yang saat ini dijadikan sebagai tolak ukur keunggulan daya saing bagi setiap perusahaan.

Pada dasarnya, kepuasan atau ketidak puasan konsumen merupakan 
perbedaan antara harapan dan kinerja yang dirasakan. Jadi, pengertian kepuasan nasabah barati bahwa kinerja suatu barang sekurang-kurangnya sama dengan apa yang diharapkan guna untuk memenangkan ataupun meningkatkan persaingan yang ada. Seperti seorang nasabah, menginginkan prosedur pelayanan yang cepat dan tepat, akan tetapi pada kenyataannya sering berbelit-belit atau terlalu panjang birokrasinya, sehingga menimbulkan rasa kecewa dan ketidakpuasan.

Peningkatan dan penurunan kualitas dan nilai pelayanan bank kepada nasabah senantiasa mewarnai kegiatan dunia usaha perbankan dewasa ini. Hal ini mendorong upaya pengukuran dalam pengembangan strategi pemasaran, yang tentunya akan mempengaruhi aktivitas jual beli jasa-jasa perbankan baik dalam usaha perkreditan maupun upaya penghimpunan dana masyarakat. Sehubungan dengan hal tersebut, maka proses pengukuran dimulai dari penentuan siapa yang menjadi pelanggan, kemudian dipantau dari tingkat kualitas dan nilai yang diinginkan dan pada akhirnya menjadi formulasi strategi. Juga dianalisis tentang bagaimana posisi pesaing dan kemampuan perusahaan. Artinya apakah pimpinan perusahaan telah memperlihatkan dengan seksama tentang nilai hal-hal apa saja yang dianggap penting oleh nasabah, yang dapat memberikan kepuasan pada mereka. Kalau kinerja dari kualitas dan nilai kegunaan yang dihasilkan bagus, maka tentunya akan berarti dapat memberikan kepuasan. Melalui kualitas dan nilai pelayanan yang diberikan baik, maka diharapkan akan dapat meningkatkan jumlah keuntungan bank sekaligus dapat meningkatkan persaingan yang memilih bank Swasta "XYZ" Cabang Pekanbaru sebagai tempat penyimpanan dananya. Selain itu secara lebih luas dapat dipergunakan untuk segala keperluan perbankan lainnya.

\section{Perumusan Masalah}

Berdasarkan latar belakang tersebut di atas, maka dapat diidentifikasikan rumusan masalahnya sebagai berikut:

1. Bagaimanakah tingkat kualitas pelayanan jasa bank nasabah pada Bank Swasta "XYZ" Cabang Pekanbaru.

2. Bagaimanakah pengaruh tingkat kualitas pelayanan jasa bank terhadap peningkatan jumlah keuntungan pada Bank Swasta "XYZ" Cabang Pekanbaru.

\section{Tujuan Penelitian}

Penelitian ini bertujuan adalah:

1. Untuk mengetahui tingkat kualitas pelayanan jasa bank nasabah pada Bank Swasta "XYZ" Cabang Pekanbaru.

2. Untuk mengetahui pengaruh kualitas pelayanan jasa bank terhadap peningkatan jumlah ,"m keuntungan pada Bank Swasta "XYZ" Cabang Pekanbaru

\section{Tinjauan Pustaka}

Konsep manajemen pemasaran dewasa ini berorientasi pada kebutuhan dan keinginan konsumen, serta pengembangan produk dan jasa yang bertujuan untuk memuaskan kebutuhan dan keinginan konsumen. Nasabah adalaha salah satu dari perilaku dan 
kekuatan pasar perbankan yang tidak dapat dikontrol. Oleh karena itu kunci bagi bank untuk dapat tetap mempertahankan profitabilitas dan pertumbuhannya serta pangsa pasarnya dalam lingkungan pemasaran dengan tingkat persaingan tinggi adalah kemampuan bank untuk mengidentifikasi dan memuaskan kebutuhan serta keinginan nasabah lebih baik dan lebih cepat dari pesaingnya. Salah satu cara untuk mengidentifikasi kebutuhan dan keinginan nasabah adalah melalui riset perilaku nasabah.

Relevansi perilaku konsumen atau nasabah dengan manajemen pemasaran menurut Loudon dan Della Bitta (1993: 11), serta Kotler (1994: 173) adalah penggunaannya dalam hal:

1. Melakukan analisis peluang pasar (market opprtunity analysis), yaitu meneliti keadaaan dan kecenderungan pasar untuk mengidentifikasi keinginan dan kebutuhan konsumen yang belum terpuaskan.

2. Melakukan pemilihan pasar sasaran (target market selection) untuk mengidentifikasi sekelompok konsumen yang mempunyai kebutuhan dan keinginan yang unik.

3. Menentukan bauran pemasaran (marketing mix determination).

Untuk mengatasi pelayanan terhadap nasabah dan mengatasi persaingan yang ada, maka bank Swasta "XYZ" Cabang Pekanbaru dirasakan perlu untuk mengadakan perubahan dari setiap aspek kualitas dan nilai pelayanan perbankan, aspek penting yang dirasakan perlu adalah dalam hal:
1. Pembenahan organisasi serta sistem kerja dan menambah ketrampilan para karaywannya.

2. Persaingan antar bank, baik dalam pengumpulan dana dan khususnya bunga deposito semakin hari semakin kompetitif.

3. Perkembangan sarana dan prasarana Bank Swasta "XYZ" Cabang Pekanbaru.

Untuk meningkatkan kualitas pelayanan dan nilai pelayanan perbankan dan untuk menumbuhkan loyalitas nasabah hal-hal yang perlu dilaksanakan selain hal tersebut di atas adalah sebagai berikut:

1. Dalam memasarkan produknya, Bank Swasta "XYZ" Cabang Pekanbaru harus melaksanakan atas dasar konsep pemasaran.

2. Bank perlu melaksanakan strategi pemasaran yang efektif dan efisien.

3. Agar dapat memenangkan persaingan atau setidak-tidaknya dapat mempertahankan eksistensinya dalam era persaingan sekarang ini, bank harus secara terus menerus meningkatkan kualitas pelayanannya.

Kualitas pelayanan yang digambarkan pada kepuasan nasabah merupakan sesuatu yang mudah harus dikelola dengan sebaik-baiknya dan merupakan prioritas utama khususnya bagi perusahaan yang bergerak di bidang jasa, agar dicapai suatu tingkat yang sesuai antara apa yang diharapkan oleh nasabah dengan apa yang dilaksanakan oleh perusahaan. Dalam hal ini, perusahaan perbankan haruslah memperhatikan dengan seksama nilainilai yang dianggap penting oleh nasabah, agar nasabah menjadi puas dan 
perusahaan tetap survive, yang pada gilirannya akan dicapai tujuan yang diharapkan oleh perusahaan yakni adanya peningkatan jumlah tabungan nasabah.

Apalagi bagi perusahaan yang bergerak di bidang jasa pelayanan perbankan yang ditujukan bagi mereka yang memerlukan pengurusan dan prosedur, kualitas dan nilai pelayanan menjadi sesuatu hal yang sangat berarti bagi mereka. Karena pelayanan yang berkualitas merupakan sebagian dari kepuasan mereka. Untuk itu, maka perusahaan perlu menilai setiap faktor yang mempengaruhi kepuasan nasabahnya.

Kualitas pelayanan yang ditawarkan perusahaan dapat ditingkatkan melalui unsur kualitas jada (service quality elements). Menurut Parasuraman, Zeithaml, dan Berry (1996: 81) menyatakan "lima unsur yang menentukan kualitas jasa yaitu, tangibel, responsiveness, reliability, assurance, dan emphaty". Tangibles mencerminkan fasilitas fisik jasa seperti gedung kantor, ruangan dan petugas. Reliability mencakup konsistensi dari penampilan dan keandalan jasa. Responsiveness meliputi kesiapan dan kecepat tanggapan petugas untuk menyediakan jasa. Assurance meliputi ketrampilan petugas, keramahan petugas, kepercayaan, keamanan dalam penggunaan jasa. Emphaty mencakup kemudahan, komunikasi, dan pemahaman terhadap kebutuhan nasabah. Dengan demikian kualitas pelayanan akan ditentukan oleh kemampuan perusahaan dalam menampilkan unsur-unsur kualitas jasa tersebut.
Pada dasarnya unsur-unsur dari kualitas pelayanan akan menciptakan kepuasan bagi para nasabah. Dimana menurut Jennie Siat (1997: 11) mengatakan bahwa kepuasan pelanggan (nasabah) merupakan modal dasar bagi perusahaan dalam memebntuk loyalitas pelanggan (nasabah).

Nasabah memperoleh kepuasan dalam kualitas pelayanan merupakan modal dasar bagi perusahaan dalam rangka peningkatan jumlah kruntungan bank yang pada gilirannya membentuk loyalitas nasabah. Nasabah yang loyal adalah asset yang paling berharga bagi Bank Swasta "XYZ" Cabang Pekanbaru dalam meningkatkan profitabilitas perusahaan. Menurut Griffin (1995: 4) mengatakan bahwa "Loyalty is based on behaviour and defined as non random purchase expressed over time by some decision making unit”.

Dalam industri jasa, khususnya bank, pada umumnya tidak dikenal suatu spesifik brand dari produk/jasa tertentu, karena merek dagang (brand) utama dari produk/jasa bank adalah nama bank itu sendiri atau company brand yang merupakan suatu nilai citra pelayanan; seperti yang dikatakan oleh Berry (1998: 28) bahwa "in service the company name is the brand name", artinya, loyalitas nasabah terhadap layanan suatu perusahaan, seperti halnya bank, sama artinya dengan loyalitasnya terhadap perusahaan/bank itu sendiri. Dengan demikian, semakin tinggi kepuasan pelanggan/nasabah atas pelayanan yang diterimanya, maka akan semakin baik pula persepsi nasabah terhadap bank; karena nama bank merupakan brand dari bank itu sendiri, maka yang semakin baik di mata nasabah adalah 
citra merek bank atau company brand image.

Seperti dikemuakan oleh Aaker (1991, 109-110) bahwa "brand image is a set of association, usually organized in some meningful way". Artinya, apabila segala sesuatu yang menyangkut aktivitas suatu bank yang merupakan nilai pelayanannya; misalnya tampilan gedung dan counter pelayanan, tempat parkir yang luas, kecapatan pelayanan, warna seragam pegawainya. Logo bank; telah diassosiasikan baik oleh nasabah, maka nama bank tersebut akan dianggap atau dipersepsikan baik oleh konsumennya maupun masyarakat pada umumnya yang merupakan sesuatu yang disebut "superior perceived value".

Dari uraian-uraian di atas, maka dapat dikatakan bahwa dalam strategi memasarkan jasa perlu dicapai adanya suatu Value (nilai) yang bermakna, bukan saja bagi pelanggan, namun juga bagi pihak bank itu sendiri. Menurut Hermawan Kertajaya (1995: 301) dalam kerngka kerja "The Strategic Marketing Plus 2000" menyatakan bahwa Value Creation bagi perusahaan akan tercipta melalui Brand, Service dan Process. Brand merupakan valuei pertama. Pada dasarnya yang dibeli oleh pelanggan adalah brand bukan produknya. Oleh karena itu perusahaan harus benar-benar mengembangkan brand tesebut agar dipersepsi oleh pelanggan mempunyai value yang tinggi. Hal ini dapat tercapai apabila ibrandi tersebut bukan saja dikenal, tetapi juga memiliki asosiasi yang positif serta mempunyai perceived quality yang baik. Value kedua adalah Service, yang merupakan salah satu sumber untuk menciptakan customer value yang paling potensial dan relatif lebih sulit untuk ditiru oleh para pesaing. Value yang ketiga adalah Process, yaitu bahwa setiap karyawan dalam suatu perusahaan harus terlibat dalam proses pemuasan pelanggan untuk mewujudkan perusahaan tersebut untuk menjadi "value-adding company".

\section{Hipotesis}

Atas dasar perumusan masalah, tujuan penelitian dan tinjauan pustaka di atas, maka dapat dikemukakan hipotesis penelitian secara umum yaitu: "Kualitas Pelayanan Jasa Bank Mempunyai Pengaruh Yang Signifikan baik Secara Serentak maupun Parsial Terhadap Peningkatan Jumlah Keuntungan Bank Swasta "XYZ" Cabang Pekanbaru".

\section{Metode Penelitian}

Penelitian ini merupakan penelitian survey, yaitu penelitian yang mengambil sampel dari populasi dan menggunakan kuesioner sebagai alat pengumpulan data yang pokok. Pada umumnya yang merupakan unit analisis dalam penelitian survey adalah individu (Singarimbun, 1995). Oleh karena itu unit analisisnya adalah jasa-jasa pelayanan bank sebagai individu. Jenis penelitian ini adalah Causal Research dimana tujuan utamanya untuk mencari hubungan sebab akibat antara variabel independen dengan variabel dependen yang dilakukan dengan pengujian hipotesis (Widayat, et. al, 2002).

\section{Definisi Operasional Variabel}

Seperti yang terungkap di dalam objek penelitian, bahwa pokok masalah yang diteliti adalah bersumber pada dua hal yaitu kualitas pelayanan jasa bank 
sebagai variabel bebas (variabel $\mathrm{X}$ ) dan peningkatan jumlah keuntungann bank sebagai variabel tidak bebas/terikat (variable Y). Secara rinci, operasionalisasi variabel dalam penelitian ini dapat dilihat pada tabel 1

\section{Jenis dan Sumber Data}

Jenis data yang diperlukan dalam penelitian ini adalah data primer dan data sekunder. Sumber data primer diperoleh dari hasil penelitian secara empirik melalui penyebaran kuesioner kepada nasabah dana selaku responden dan kepada pihak manajemen khususnya. Sedangkan sumber data sekunder diantaranya diperoleh dari laporan tahunan tentang profil Bank Swasta "XYZ" Cabang Pekanbaru, laporan keuangan jasa-jasa bank, dan buku panduan produk.

\section{Metode Pengumpulan Data}

Responden penelitian ini adalah nasabah-nasabah yang telah memiliki tabungan di Bank Swasta "XYZ" Cabang Pekanbaru. Pengambilan sampel dilakukan secara acak sederhana (simple random sampling), yang artinya subjek dalam populasi dicampur sehingga semua subjek dianggap sama (homogen) dan mempunyai kesempatan yang sama untuk dipilih. Sampel yang diambil sebanyak 100 responden dari populasi nasabah Bank Swasta "XYZ" Cabang Pekanbaru yang aktif sebanyakl 33.122 orang,. Penentuan jumlah sampel menggunakan pendekatan dari Slovin (Husein Umar, 1999).

Tabel 1

Operasionalisasi Variabel

\begin{tabular}{|c|c|l|l|c|}
\hline Variabel & $\begin{array}{c}\text { Sub } \\
\text { Variabel }\end{array}$ & \multicolumn{1}{|c|}{ Konsep Variabel } & \multicolumn{1}{|c|}{ Indikator } & Skala \\
\hline $\begin{array}{c}\text { Kualitas } \\
\text { Pelayana } \\
\text { n (Xi) }\end{array}$ & $\begin{array}{l}\text { Suatu entitas untuk } \\
\text { dapat memenuhi dan } \\
\text { memuaskan kebutuhan } \\
\text { dan keinginan nasabah } \\
\text { sesuai dengan yang } \\
\text { diharapkan }\end{array}$ & & \\
\hline & $\begin{array}{c}\text { Tangible } \\
\text { (Bukti } \\
\text { Langsung) } \\
=\mathrm{X}_{1}\end{array}$ & $\begin{array}{l}\text { Sarana dan prasarana } \\
\text { dan fasilitas baik fisik } \\
\text { maupun personel }\end{array}$ & $\begin{array}{l}\text { Parkir; Ruangan } \\
\text { tunggu; Interior dan } \\
\text { ekstreior; penampilan } \\
\text { karyawan; tampilan } \\
\text { gedung }\end{array}$ & $\begin{array}{c}\text { Ordina } \\
1\end{array}$ \\
\hline $\begin{array}{c}\text { Reliability } \\
\text { Kehandal } \\
\text { an) }=\mathrm{X}_{2}\end{array}$ & $\begin{array}{l}\text { kencerminkan suatu } \\
\text { kelaksananan untuk } \\
\text { pelayanan yang } \\
\text { dijanjikan kepada } \\
\text { nasabah dengan tepat } \\
\text { dan terpercaya }\end{array}$ & $\begin{array}{l}\text { Ketepatan; Kecepatan } \\
\text { dan Kesesuaian } \\
\text { pemberian pelayanan } \\
\text { dengan standar yang } \\
\text { ada }\end{array}$ & $\begin{array}{c}\text { Ordina } \\
1\end{array}$ \\
\hline
\end{tabular}




\begin{tabular}{|c|c|c|c|c|}
\hline & $\begin{array}{l}\text { Responsiv } \\
\text { enes } \\
\text { (Daya } \\
\text { Tanggap) } \\
=\mathrm{X}_{3} \\
\end{array}$ & $\begin{array}{l}\text { Kesiapan dan } \\
\text { ketanggapan para } \\
\text { pelaksana atau } \\
\text { karyawan }\end{array}$ & $\begin{array}{l}\text { Kecepatan dan } \\
\text { ketanggapan dalam } \\
\text { merespons keluhan } \\
\text { dan permintaan } \\
\text { nasabah } \\
\end{array}$ & $\begin{array}{c}\text { Ordina } \\
1\end{array}$ \\
\hline & $\begin{array}{l}\text { Assurance } \\
\text { (Jaminan) } \\
\quad=\mathrm{X}_{4}\end{array}$ & $\begin{array}{l}\text { Kemampuan dan } \\
\text { Ketrampilan serta } \\
\text { Keramahan dalam } \\
\text { pemberian pelayanan } \\
\text { nasabah }\end{array}$ & $\begin{array}{l}\text { Ketrampilan; } \\
\text { kemampuan; } \\
\text { Keramahan; dan } \\
\text { Pengetahuan }\end{array}$ & $\begin{array}{c}\text { Ordina } \\
1\end{array}$ \\
\hline & $\begin{array}{l}\text { Emphaty } \\
\quad=\mathrm{X}_{5}\end{array}$ & $\begin{array}{l}\text { Perhatian dalam } \\
\text { memahami kebutuhan } \\
\text { dan keinginan nasabah }\end{array}$ & $\begin{array}{l}\text { Kemampuan } \\
\text { karyawan dalam } \\
\text { memenuhi kebutuhan } \\
\text { dan keinginan } \\
\text { nasabah; serta } \\
\text { Mengenal dengan } \\
\text { baik nasabah; } \\
\text { Kepedulian kepada } \\
\text { nasabah }\end{array}$ & $\begin{array}{c}\text { Ordina } \\
1\end{array}$ \\
\hline $\begin{array}{l}\text { Peningka } \\
\quad \tan \\
\text { Jumlah } \\
\text { Keuntung } \\
\text { an }(\mathrm{Y})\end{array}$ & & $\begin{array}{l}\text { Jumlah nasabah yang } \\
\text { diharapkan dengan } \\
\text { sejumlah dana yang } \\
\text { dapat dihimpun oleh } \\
\text { pihak bank dan dihitung } \\
\text { dengan ROA }\end{array}$ & & Ratio \\
\hline
\end{tabular}

\section{Teknik Pengumpulan Data}

Sumber data yang diperoleh penulis dengan menggunakan teknik sebagai berikut:

a. Wawancara, adalah cara pengumpulan data dan informasi dengan cara melakukan tanya jawab secafra langsung dengan pihk-pihak yang bersangkutan guna mendapatkan data dan keterangan yang menunjang analisis dalam penelitian

b. Kuesioner, daftar pertanyaan yang dibuat dalam bentuk sederhana dengan metode pertanyaan tertutup yang diberikan kepada pihak responden, sehingga memperoleh data yang berhubungan dengan masalah yang diteliti.

c. Observasi, mengamati kegiatan perusahaan yang berhubungan dengan masalah yang sedang diteliti.

\section{Analisis Data}

Untuk membuktikan hipotesis penelitian (menguji pengaruh kualitas dan nilai pelayanan terhadap peningkatan jumlah keuntungan Bank Swasta "XYZ" Cabang Pekanbaru), maka dilakukan dengan menguji koefisien determinasi $\left(\mathrm{R}^{2}\right)$, yang di uji signifikansinya dengan uji $\mathrm{F}$, hasil uji $\mathrm{F}$ 
bermakna bilamana diperoleh harga $\mathrm{p}<$ 0,05 atau $F_{\text {hitung }}>F_{\text {tabel }}$.

Untuk menghitung berapa besar pengaruh variabel bebas secara bersamasama (simultan) terhadap variabel terikat, dapat dilihat dari Koefisien Determinasi Berganda $\left(\mathrm{R}^{2}\right)$ dengan menggunakan rumus sebagai berikut: (Walpole, 1990: 357)

$$
\mathrm{R}^{2}=\frac{\mathrm{JKR} \text { (jumlah kuadrat regresi) }}{\mathrm{JKT} \text { (jumlah kuadrat total) }}
$$

Untuk membuktikan apakah Koefisien Determinasi Multiple ini siginifikan atau tidak dipergunakan uji $\mathrm{F}$ dengan rumus sebagai berikut: (Sudjana, 1991: 75)

$$
\mathrm{F}=\frac{\mathrm{R}^{2} / \mathrm{k}}{\left(1-\mathrm{R}^{2}\right) /(\mathrm{n}-\mathrm{k}-1)}
$$

Level of significant $(\alpha)=5 \%$

dimana :

$\mathrm{R}^{2}=$ Koefisien Determinasi

$\mathrm{k}$ = Banyaknya variabel bebas (Xi)

$\mathrm{n}$ = Ukuran sampel (sample size)

Paramater ( $\mathrm{n}-\mathrm{k}-1)$ berguna untuk mencari nilai tabel dari uji $\mathrm{F}\left(\mathrm{F}_{\text {tabel }}\right)$ pada tingkat significant yang ditentukan oleh $(\alpha)$. Nilai $F_{\text {tabel }}$ kemudian dibandingkan dengan $F_{\text {hitung }}$ dan keputusan diambil berdasarkan:

1. Memiliki keberartian yang bermakna jika $F_{\text {hitung }}>F_{\text {tabel }}$.

2. Tidak memiliki keberartian yang bermakna jika $\mathrm{F}_{\text {hitung }}<\mathrm{F}_{\text {tabel }}$.

Kesimpulan :

Jika $\mathrm{F}_{\mathrm{o}}<\mathrm{F}_{\mathrm{t}}$ maka $=\mathrm{H}_{\mathrm{o}}$ diterima ; $\mathrm{H}_{\mathrm{a}}=$ ditolak

Artinya; Variasi dari pada model regresi tidak berhasil menerangkan variasi variabel bebas secara keseluruhan sejauh mana pengaruhnya terhadap variabel terikat.

Sebaliknya :

Jika $\mathrm{F}_{\mathrm{o}}>\mathrm{F}_{\mathrm{t}}$ maka $=\mathrm{H}_{\mathrm{o}}$ ditolak

$$
=\mathrm{H}_{\mathrm{a}} \text { diterima }
$$

Artinya; Variasi dari pada model regresi berhasil menerangkan variasi variabel bebas secara keseluruhan sejauh mana pengaruhnya terhadap variabel terikat.

Sedangkan untuk mengetahui berapa besar pengaruh masing-masing (parsial) variabel bebas $\left(\mathrm{X}_{\mathrm{i}}\right)$ terhadap variabel terikat $\left(\mathrm{Y}_{\mathrm{i}}\right)$, dapat dilihat dari nilai Koefisien Determinasi Parsialnya $\left(\mathrm{r}^{2}\right)$ dengan rumus sebagai berikut: (Sudjana, 1992: 368)

$$
\mathrm{r}^{2}=\frac{\left.\sum \mathrm{W}_{\mathrm{i}}-\mathrm{Y}^{\boldsymbol{\gamma}}-\sum \mathrm{Y}_{\mathrm{i}} \mathrm{i}^{\mathrm{t}}-\mathrm{Y}_{\mathrm{i}}\right)^{2}}{\sum \mathrm{U}_{\mathrm{i}}-\mathrm{Y}^{\boldsymbol{\gamma}}}
$$

Selanjutnya koefisien korelasi (r) adalah koefisien korelasi parsial antara variabel bebas $\left(\mathrm{X}_{\mathrm{i}}\right)$ dengan variabel terikat $\left(Y_{i}\right)$ dengan anggapan variabel $X_{i}$ lainnya konstan dengan rumus sebagai berikut:

$$
r=\frac{n \sum X_{i} Y-\left(\sum X_{i}\right)\left(\sum Y_{i}\right)}{\sqrt{\frac{1}{m} X_{i}^{2}-\left(\sum X_{i}\right)^{2}} \frac{1}{\sum} \sum Y_{i}^{2}-\left(\sum Y_{i}\right)^{2}} .
$$

Untuk mencari nilai $t_{0} \quad\left(t_{\text {hitung }}\right)$ digunakan rumus sebagai berikut:

$$
\mathrm{t}_{\mathrm{o}}=\frac{\mathrm{r} \sqrt{(\mathrm{n}-\mathrm{k}-1)}}{\sqrt{1-\mathrm{r}^{2}}}
$$

Selanjutnya untuk membuktikan pengaruh masing-masing (parsial) variabel bebas $\left(\mathrm{X}_{\mathrm{i}}\right)$ terhadap variabel terikat $\left(\mathrm{Y}_{\mathrm{i}}\right)$ dalam penelitian ini, maka masing-masing koefisien regresinya di uji dengan uji $t$, hasil uji t bermakna bilamana diperoleh harga $\mathrm{p}<0,05$. Untuk mengetahui pengaruh yang paling dominan dari hasil uji t dapat dilihat dari 
harga $p$ yang terkecil, hal tersebut berarti pengaruhnya dominan.

Kebermaknaan pengaruh ditetap-kan dari perbandingan antara $t_{\text {hitung }}$ dengan $t_{\text {tabel}}$. Jika $t_{\text {hitung }}<t_{\text {tabel }}$ berarti tidak ada kebermaknaan pengaruh variabel babas $\left(\mathrm{X}_{\mathrm{i}}\right)$ terhadap variabel terikat $\left(\mathrm{Y}_{\mathrm{I}}\right)$.

Sebaliknya jika $t_{\text {hitung }}>t_{\text {tabel }}$ berarti variabel bebas $\left(\mathrm{X}_{\mathrm{I}}\right)$ memiliki pengaruh yang bermakna terhadap variabel terikat $\left(\mathrm{Y}_{\mathrm{i}}\right.$.

Kesimpulan :

Jika $\mathrm{t}_{\mathrm{o}}<\mathrm{t}_{\mathrm{t}}$ maka $=\mathrm{H}_{\mathrm{o}}$ diterima

$$
=\mathrm{H}_{\mathrm{a}} \text { ditolak }
$$

Artinya:

a. Variabel bebas tidak dapat menerangkan variabel terikat.

b. Tidak ada pengaruh di antara dua variabel yang diuji.

Sebaliknya :

Jika $\mathrm{t}_{\mathrm{o}} \geq \mathrm{t}_{\mathrm{t}}$ maka $=\mathrm{H}_{\mathrm{o}}$ ditolak

$=\mathrm{H}_{\mathrm{a}}$ diterima

Artinya :

a. Variabel bebas dapat menerangkan variabel tidak bebas.

b. Ada pengaruh di antara dua variabel yang diuji.

\section{Hasil Penelitian dan Pembahasan}

Hipotesis dalam penelitian ini adalah bahwa kualitas dan nilai pelayanan berpengaruh positif terhadap peningkatan jumlah keuntungan Bank Swasta "XYZ" Cabang Pekanbaru. Kualitas Pelayanan Jasa Bank merupakan variabel bebas yang terdiri dari 5 (lima) sub variabel, yaitu: Tangible $\left(\mathrm{X}_{1}\right), \quad$ Reliablity $\left(\mathrm{X}_{2}\right)$, Responsiveness $\left(\mathrm{X}_{3}\right)$, Assurance $\left(\mathrm{X}_{4}\right)$, dan Emphaty $\left(\mathrm{X}_{5}\right)$,. Sedangkan peningkatan jumlah keuntungan Bank Swasta "XYZ" Cabang Pekanbaru merupakan variabel tidak bebas (Y). Pengujian hipotesis penelitian ini dilakukan dengan menggunakan uji statistika analisis jalur (Path Analisys).

Untuk mengetahui pengaruh variabel bebas tersebut $\left(\mathrm{X}_{1} \ldots \mathrm{X}_{5}\right)$ terhadap variabel tidak bebas (Y), dilakukan dengan menganalisis hubungan pengaruh antar total skor item variabel bebas $\left(\mathrm{X}_{1} \ldots \mathrm{X}_{5}\right)$ dan $\mathrm{Y}$. Sedangkan untuk menguji hipotesis, dihitung besarnya koefisien jalur masing-masing variabel. Berdasarkan hasil perhitungan analisis statistika yang didasarkan kepada angka-angka dari masing-masing variabel dan dilakukan dengan menggunakan uji statistika, diperoleh matriks koefisien korelasi antar variabel bebas $\left(\mathrm{X}_{1} \ldots \mathrm{X}_{5}\right)$ dan $\mathrm{Y}$ sebagaimana ditunjukkan dalam tabel 1 berikut:

Tabel 1

Matriks Koefisien Korelasi Antara Variabel $\left(\mathrm{X}_{1} \ldots \mathrm{X}_{5}\right)$ dan $\mathrm{Y}$

\begin{tabular}{|c|c|c|c|c|c|}
\hline & $\mathrm{X}_{1}$ & $\mathrm{X}_{2}$ & $\mathrm{X}_{3}$ & $\mathrm{X}_{4}$ & $\mathrm{X}_{5}$ \\
\hline $\mathrm{X}_{1}$ & 1.000 & $-0,205$ & $-0,281$ & $-0,267$ & $-0,481$ \\
\hline $\mathrm{X}_{2}$ & $-0,205$ & 1,000 & 0,189 & $-0,145$ & 0,196 \\
\hline $\mathrm{X}_{3}$ & $-0,281$ & 0,189 & 1,000 & $-0,062$ & 0,129 \\
\hline $\mathrm{X}_{4}$ & $-0,267$ & 0,145 & $-0,062$ & 1,000 & 0,270 \\
\hline $\mathrm{X}_{5}$ & $-0,481$ & 0,196 & 0,129 & 0,270 & 1,000 \\
\hline $\mathrm{Y}$ & $-0,084$ & 0,257 & 0,199 & $-0,217$ & 0,260 \\
\hline
\end{tabular}

Sumber: Data olahan dengan SPSS 
Uji keberartian koefisien korelasi antar variabel $\left(\mathrm{X}_{1} \ldots \mathrm{X}_{5}\right)$ dengan hipotesis sebagai berikut:

Ho $: \rho X i X j=0$

Hi $\quad: \rho X i X j \neq 0$

Dengan menggunaakan tabel distribusi t, untuk $\alpha=5 \%, \mathrm{df}=\mathrm{n}-\mathrm{k}-1=94$, maka diperoleh $\mathrm{t}_{\text {tabel }}=\mathrm{t}_{(1-\alpha / 2 ; \mathrm{n}-\mathrm{k}-1)}=\mathrm{t}_{(0,025 ; 98)}=$ 1,9845

Dengan membandingkan $t$ hitung dan $t$ tabel, maka dapat dibuat rangkuman dari uji variabel kualitas dan nilai pelayanan sebagaimana tercantum dalam tabel 2 berikut:

Tabel 2

Pengujian Hubungan Antar Variabel Bebas $\left(\mathrm{X}_{1} \ldots \mathrm{X}_{8}\right)$

\begin{tabular}{|c|c|c|c|c|}
\hline \multicolumn{2}{|c|}{ Koefisien Korelasi } & $\mathrm{t}_{\text {hitung }}$ & $\mathrm{t}_{\text {tabel }}$ & Kesimpulan \\
\hline rX1X2 & $-0,2045$ & $-2,0682$ & $-1,9845$ & Terdapat hubungan X1 dan X2 \\
\hline rX1X3 & $-0,2809$ & $-2,8972$ & $-1,9845$ & Terdapat hubungan X1 dan X3 \\
\hline rX1X4 & $-0,2668$ & $-2,7411$ & $-1,9845$ & Terdapat hubungan X1 dan X4 \\
\hline rX1X5 & $-0,4810$ & $-5,4306$ & $-1,9845$ & Terdapat hubungan X1 dan X5 \\
\hline rX2X3 & 0,1889 & $1,-046$ & 1,9845 & $\begin{array}{c}\text { Tidak Terdapat hubungan X2 dan } \\
\text { X3 }\end{array}$ \\
\hline rX2X4 & $-0,1451$ & $-1,4519$ & $-1,9845$ & $\begin{array}{c}\text { Tidak Terdapat hubungan X2 dan } \\
\text { X4 }\end{array}$ \\
\hline rX2X5 & 0,1960 & 1,9790 & 1,9845 & $\begin{array}{c}\text { Tidak Terdapat hubungan X2 dan } \\
\text { X5 }\end{array}$ \\
\hline rX3X4 & $-0,0615$ & $-0,6104$ & $-1,9845$ & $\begin{array}{c}\text { Tidak Terdapat hubungan X3 dan } \\
\text { X4 }\end{array}$ \\
\hline rX3X5 & 0,1292 & 1,2901 & 1,9845 & $\begin{array}{c}\text { Tidak Terdapat hubungan X3 dan } \\
\text { X5 }\end{array}$ \\
\hline rX4X5 & 0,2695 & 2,7702 & 1,9845 & Terdapat hubungan X4 dan X5 \\
\hline
\end{tabular}

Sumber: Data olahan dengan SPSS

Dari hasil perhitungan koefisien korelasi dan uji kemaknaan di atas ternyata ada beberapa variabel yang mempunyai koefisien korelasi signifikan dan tidak signifikan, artinya terhadap hubungan dan tidak ada hubungan antara variabel-avariabel kualitas dan nilai pelayanan sehingga perhitungan dapat dilanjutkan untuk menentukan koefisien jalur.

Koefisien jalur ditentukan dengan rumus:

$k$

$$
P_{Y X i}=\sum C r_{i j} r_{Y X j}
$$

dimana $i=1, \ldots .8$

$$
J=1
$$

Pengaruh secara keseluruhan variabel $\mathrm{X}_{1}$ sampai $\mathrm{X}_{5}$ adalah:

$$
\begin{aligned}
& R_{Y X 1 \ldots X 4}^{2} \\
& 0,6399
\end{aligned}=\underset{J=1}{\sum P Y X_{j} r Y X_{j}}=
$$


Sedangkan koefisien jalur di luar variabel $\mathrm{X}_{1}$ sampai $\mathrm{X}_{5}$ ditentukan melalui rumus:

$P Y \varepsilon=\sqrt{ } 1-\mathrm{R}^{2}{ }_{\mathrm{YX} 1 \ldots \mathrm{X} 5}=0,614$

Berdasarkan hasil perhitungan di atas, dapat diartikan bahwa variabel Tangible $\left(\mathrm{X}_{1}\right), \quad$ Reliablity $\left(\mathrm{X}_{2}\right)$, Responsiveness $\left(\mathrm{X}_{3}\right)$, Assurance $\left(\mathrm{X}_{4}\right)$, dan Emphaty $\left(\mathrm{X}_{5}\right)$, secara bersama-sama mempengaruhi tingkat keuntungan bank (Y) sebesar 63,99\% dan sisanya sebesar $36,01 \%$ dipengaruhi oleh faktor lain yang tidak masuk ke dalam penelitian ini.

Didasarkan pada kerangka teori bahwa terdapat pengaruh positif antara kualitas pelayanan jasa bank terhadap pertumbuhan jumlah tabungan, maka perlu diuji hipotesis tersebut secara keseluruhan dengan bentuk sebagai berikut:

Ho: $\operatorname{Pyx} 1=\operatorname{Pyx} 2=\ldots . .=\operatorname{Pyx} 5=0$ (secara keseluruhan variabel bebas tidak berpengaruh terhadap variabel tidak bebasnya)

Hi : sekurang-kurangnya ada sebuah Pyxi $\neq 0$

Dari tabel distribusi $\mathrm{F}$, diperoleh $\mathrm{F}$ tabel $=2,0418$. Karena F hitung lebih besar dari pada $\mathrm{F}$ tabel, maka Ho ditolak dan Hi diterima, artinya variabel kualitas pelayanan jasa bank $\left(\mathrm{X}_{1} \ldots \mathrm{X}_{5}\right)$ secara bersama-sama berpengaruh terhadap pertumbuhan jumlah tabungan pada taraf nyata $\propto=5 \%$. Dengan demikian pengujian hipotesis dalam penelitian ini secara individual dapat dilakukan.

Pengujian hipotesis untuk setiap variabel bebas $\left(\mathrm{X}_{1} \ldots \mathrm{X}_{5}\right)$ terhadap variabel tidak bebas (Y) adalah sebagai berikut:

Ho : Pyx $1 \leq 0 \quad$ (Xi tidak berpengaruh terhadap $\mathrm{Y}$ )

Hi : Pyx $1>0 \quad$ (Xi berpengaruh terhadap Y)

Kriteria pengambilan keputusan:

Jika $t_{o i} \geq \mathrm{t}$ tabel, maka Ho ditolak (pengujian signifikan)

Jika $t_{o i}<\mathrm{t}$ tabel, maka Ho diterima (pengujian tidak signifikan)

Dari hasil pengujian hipotesis dengan menggunakan analisis statistika untuk mengetahui pengaruh dari setiap variabel bebas $\left(\mathrm{X}_{1} \ldots \mathrm{X}_{5}\right)$ terhadap pertumbuhna jumlah tabungan (Y) dapat dirangkum pada tabel 3 berikut: 
Tabel 3

Hasil Perhitungan Pengaruh Variabel $\left(\mathrm{X}_{1} \ldots \mathrm{X}_{5}\right)$ Terhadap $\mathrm{Y}$

\begin{tabular}{|c|c|c|c|c|}
\hline \multicolumn{2}{|c|}{ Koefisien Korelasi } & $t_{\text {hitung }}$ & $\mathrm{T}_{\text {table }}$ & Kesimpulan \\
\hline $\mathrm{P}_{\mathrm{YX} 1}$ & 0,0746 & 0,9569 & 1,6618 & $\begin{array}{l}\text { Ho diterima, Hi ditolak (tidak terdapat } \\
\text { pengaruh positif } \mathrm{X}_{1} \text { terhadap } \mathrm{Y} \text { ) }\end{array}$ \\
\hline $\mathrm{P}_{\mathrm{YX} 2}$ & 0,0573 & 0,8440 & 1,6618 & $\begin{array}{l}\text { Ho diterima, Hi ditolak (tidak terdapat } \\
\text { pengaruh positif } \mathrm{X}_{2} \text { terhadap } \mathrm{Y} \text { ) }\end{array}$ \\
\hline $\mathrm{P}_{\mathrm{YX} 3}$ & 0,1037 & 1,5402 & 1,6618 & $\begin{array}{l}\text { Ho diterima, Hi ditolak (tidak terdapat } \\
\text { pengaruh positif } \mathrm{X}_{3} \text { terhadap } \mathrm{Y} \text { ) }\end{array}$ \\
\hline $\mathrm{P}_{\mathrm{YX} 4}$ & 0,0026 & 0,0352 & 1,6618 & $\begin{array}{l}\text { Ho diterima, Hi ditolak (tidak terdapat } \\
\text { pengaruh positif } \mathrm{X}_{4} \text { terhadap } \mathrm{Y} \text { ) }\end{array}$ \\
\hline PYX5 & 0,0206 & $-0,2560$ & 1,6618 & $\begin{array}{l}\text { Ho diterima, Hi ditolak (tidak terdapat } \\
\text { pengaruh positif } X_{5} \text { terhadap } Y \text { ) }\end{array}$ \\
\hline
\end{tabular}

Sumber: Data olahan dengan SPSS

Pengaruh Variabel Tangible $\left(\mathbf{X}_{1}\right)$ Terhadap Peningkatan Jumlah Keuntungan Bank

Berdasarkan hasil perhitungan statistik, dapat terungkap pengaruh variabel Tangible terhadap peningkatan jumlah keuntungan bank sebagaimana tampak pada tabel 4. Dari tabel tersebut, terlihat bahwa pengaruh variabel Tangible terhadap peningkatan jumlah keuntungan bank secara langsung sebesar
$0,557 \%$. Sedangkan pengaruh tidak langsung terbesar adalah melalui variabel Emphaty sebesar 0,074\%., dan pengaruh tidak langsung terkecil adalah melalui variabel reputation sebesar 0,576\%. Pengaruh variabel Tangible tersebut secara keseluruhan (total) mencapai $-0,629 \%$ Ini menunjukkan bahwa variabel Tangible relatif kecil pengaruhnya terhadap peningkatan jumlah keuntungan bank.

Tabel 4

Pengaruh Langsung dan Tidak langsung Dari $\mathrm{X}_{1}$ Terhadap Y

\begin{tabular}{|c|l|c|}
\hline & \multicolumn{1}{|c|}{ Interpretasi Analisis Jalur } & Pengaruh (\%) \\
\hline $\mathrm{X}_{1}$ & Pengaruh langsung ke Y & $0,557 \%$ \\
& Pengaruh tidak langsung melalui X2 ke Y & $-0,087 \%$ \\
& Pengaruh tidak langsung melalui X3 ke Y & $-0,217 \%$ \\
& Pengaruh tidak langsung melalui X4 ke Y & $-0,005 \%$ \\
& Pengaruh tidak langsung melalui X5 ke Y & $0,074 \%$ \\
& Pengaruh tidak langsung melalui X6 ke Y & $-0,576 \%$ \\
& Pengaruh tidak langsung melalui X7 ke Y & $-0,148 \%$ \\
& Pengaruh tidak langsung melalui X8 ke Y & $-0,225 \%$ \\
\hline & Jumlah & $-0,629 \%$ \\
\hline
\end{tabular}

Sumber: Data olahan dari SPSS 
Pengaruh Variabel Realibility $\left(\mathbf{X}_{2}\right)$ Terhadap Peningkatan Jumlah Keuntungan Bank

Berdasarkan pada hasil perhitungan statistik, maka dapat dijelaskan bahwa terdapat pengaruh variabel Realibility terhadap peningkatan jumlah keuntungan bank sebagaimana tampak pada tabel 5 .

Berdasarkan pada tabel 5 terlihat bahwa pengaruh variabel Realibility secara langsung sebesar $0,328 \%$. Pengaruh tidak langsung terbesar adalah melalui variabel reputation sebesar $0,848 \%$, sedangkan pengaruh tidak langsung terkecil adalah melalui variabel tangoble sebesar $-0,087 \%$. Pengaruh variabel Realibility secara keseluruhan (total) mencapai 1,465\%. Hal ini menunjukkan bahwa variabel Realibility relatif berpengaruh terhadap peningkatan jumlah keuntungan bank.

Tabel 5

Pengaruh Langsung dan Tidak langsung Dari $\mathrm{X}_{2}$ Terhadap Y

\begin{tabular}{|c|l|c|}
\hline & \multicolumn{1}{|c|}{ Interpretasi Analisis Jalur } & Pengaruh (\%) \\
\hline $\mathrm{X}_{2}$ & Pengaruh langsung ke Y & $0,328 \%$ \\
& Pengaruh tidak langsung melalui X1 ke Y & $-0,087 \%$ \\
& Pengaruh tidak langsung melalui X3 ke Y & $0,112 \%$ \\
& Pengaruh tidak langsung melalui X4 ke Y & $-0,002 \%$ \\
& Pengaruh tidak langsung melalui X5 ke Y & $-0,023 \%$ \\
& Pengaruh tidak langsung melalui X6 ke Y & $0,848 \%$ \\
& Pengaruh tidak langsung melalui X7 ke Y & $0,180 \%$ \\
& Pengaruh tidak langsung melalui X8 ke Y & $0,108 \%$ \\
\hline & Jumlah & $1,465 \%$ \\
\hline
\end{tabular}

Sumber: Data olahan dari SPSS

Pengaruh Variabel Responsiveness $\left(\mathbf{X}_{3}\right)$ Terhadap Peningkatan Jumlah Keuntungan Bank

Berdasarkan pada tabel 6 , terlihat bahwa pengaruh variabel Responsiveness terhadap peningkatan jumlah keuntungan bank secara langsung sebesar $1,075 \%$. Pengaruh tidak langsung terbesar adalah melalui variabel reputation sebesar $0,704 \%$, sedangkan pengaruh tidak langsung terkecil adalah melalui variabel tangible sebesar $-0,217 \%$. Pengaruh variabel Responsiveness secara keseluruhan (total) mencapai $2,060 \%$.. Hal ini memberikan gambaran bahwa variabel Responsiveness relatif berpengaruh terhadap peningkatan jumlah keuntungan bank.

Pengaruh Variabel Assurance $\left(\mathbf{X}_{4}\right)$ Terhadap Peningkatan Jumlah Keuntungan Bank

Dari hasil perhitungan statistika, maka dapat diungkapkan bahwa pengaruh variabel Assurance terhadap peningkatan jumlah keuntungan bank sebagaimana tampak pada tabel 7. Dari tabel 7 di atas, terlihat bahwa pengaruh variabel Assurance secara langsung sebesar $0,001 \%$. Pengaruh tidak langsung terbesar adalah melalui variabel brand loyalty sebesar 0,003\%, sedangkan pengaruh tidak langsung 
terkecil adalah melalui variabel reputation sebesar $-0,042 \%$. Pengaruh variabel Assurance terhadap peningkatan jumlah keuntungan bank secara keseluruhan (total) mencapai -
0,057\%. Hal ini memberikan gmbaran variabel Assurance relatif kecil pengaruhnya terhadap peningkatan jumlah keuntungan bank.

Tabel 6

Pengaruh Langsung dan Tidak langsung Dari $\mathrm{X}_{3}$ Terhadap $\mathrm{Y}$

\begin{tabular}{|c|l|c|}
\hline & \multicolumn{1}{|c|}{ Interpretasi Analisis Jalur } & Pengaruh (\%) \\
\hline $\mathrm{X}_{3}$ & Pengaruh langsung ke Y & $1,075 \%$ \\
& Pengaruh tidak langsung melalui X1 ke Y & $-0,217 \%$ \\
& Pengaruh tidak langsung melalui X2 ke Y & $0,112 \%$ \\
& Pengaruh tidak langsung melalui X4 ke Y & $-0,002 \%$ \\
& Pengaruh tidak langsung melalui X5 ke Y & $-0,028 \%$ \\
& Pengaruh tidak langsung melalui X6 ke Y & $0,704 \%$ \\
& Pengaruh tidak langsung melalui X7 ke Y & $0,235 \%$ \\
& Pengaruh tidak langsung melalui X8 ke Y & $0,180 \%$ \\
\hline & Jumlah & $2,060 \%$ \\
\hline
\end{tabular}

Sumber: Data olahan dari SPSS

Tabel 7

Pengaruh Langsung dan Tidak langsung Dari $\mathrm{X}_{4}$ Terhadap $\mathrm{Y}$

\begin{tabular}{|c|l|c|}
\hline & \multicolumn{1}{|c|}{ Interpretasi Analisis Jalur } & $\begin{array}{c}\text { Besar } \\
\text { Pengaruh (\%) }\end{array}$ \\
\hline $\mathrm{X}_{4}$ & Pengaruh langsung ke Y & $0,001 \%$ \\
& Pengaruh tidak langsung melalui X1 ke Y & $-0,005 \%$ \\
& Pengaruh tidak langsung melalui X2 ke Y & $-0,002 \%$ \\
& Pengaruh tidak langsung melalui X3 ke Y & $-0,002 \%$ \\
& Pengaruh tidak langsung melalui X5 ke Y & $-0,001 \%$ \\
& Pengaruh tidak langsung melalui X6 ke Y & $-0,042 \%$ \\
& Pengaruh tidak langsung melalui X7 ke Y & $-0,007 \%$ \\
& Pengaruh tidak langsung melalui X8 ke Y & $0,003 \%$ \\
\hline & Jumlah & $-0,057 \%$ \\
\hline
\end{tabular}

Sumber: Data olahan dari SPSS

Pengaruh Variabel Emphaty $\left(\mathbf{X}_{5}\right)$ Terhadap Peningkatan Jumlah Keuntungan Bank

Berdasarkan pada tabel 8 , terlihat bahwa pengaruh variabel Emphaty terhadap peningkatan jumlah keuntungan bank secara langsung sebesar $0,043 \%$. Pengaruh tidak langsung terbesar adalah melalui variabel tangible sebesar 0,074\%, sedangkan pengaruh tidak langsung terkecil adalah melalui variabel reputation sebesar $-0,452 \%$. Pengaruh variabel Emphaty secara keseluruhan (total) mencapai $-0,0536 \%$. Hal ini memberikan gmbaran variabel 
Assurance relatif kecil pengaruhnya keuntungan bank. terhadap peningkatan jumlah

Tabel 8

Pengaruh Langsung dan Tidak langsung Dari $\mathrm{X}_{5}$ Terhadap Y

\begin{tabular}{|c|l|c|}
\hline & \multicolumn{1}{|c|}{ Interpretasi Analisis Jalur } & $\begin{array}{c}\text { Besar } \\
\text { Pengaruh (\%) }\end{array}$ \\
\hline $\mathrm{X}_{5}$ & Pengaruh langsung ke Y & $0,043 \%$ \\
& Pengaruh tidak langsung melalui X1 ke Y & $0,074 \%$ \\
& Pengaruh tidak langsung melalui X2 ke Y & $-0,023 \%$ \\
& Pengaruh tidak langsung melalui X3 ke Y & $-0,028 \%$ \\
& Pengaruh tidak langsung melalui X4 ke Y & $-0,001 \%$ \\
& Pengaruh tidak langsung melalui X6 ke Y & $-0,452 \%$ \\
& Pengaruh tidak langsung melalui X7 ke Y & $-0,097 \%$ \\
& Pengaruh tidak langsung melalui X8 ke Y & $-0,052 \%$ \\
\hline & Jumlah & $-0,536 \%$ \\
\hline
\end{tabular}

Sumber: Data olahan dari SPSS

\section{Kesimpulan dan Saran}

Hasil kajian menunjukkan bahawa secara serentak kualitas dan nilai pelayanan berpengaruh secara signifikan terhadap peningkatan jumlah keuntungan Bank Swasta "XYZ" Cabang Pekanbaru. Hal ini ditunjukkan dari nilai $\mathrm{F}$ hitung lebih besar dari $\mathrm{F}$ jadual $\left(\mathrm{F}_{\text {hitung }}=20,2165>\mathrm{F}_{\text {jadual }}=2,0418\right)$. Pada masa yang sama, uji secara parsial menunjukkan bahawa nilai $t$ hitung terbesar terdapat pada variabel Responsiveness $\left(\mathrm{X}_{3}\right)$, yakni $\mathrm{t}$ hitung $=$ $7,0491>\mathrm{t}_{\text {jadual }}=1,6618$, dengan nilai $\mathrm{r}^{2}$ $=0,6508(65,08 \%)$ dan $\mathrm{p}=0,000$. Ini menunjukkan bahawa faktor Responsiveness $\left(\mathrm{X}_{3}\right)$ mempunyai pengaruh yang paling dominan terhadap peningkatan jumlah keuntungan Bank Swasta "XYZ" Cabang Pekanbaru.

Bagi memastikan kualitas dan nilai pelayanan bank Swasta "XYZ" Cabang Pekanbru mampu membawa kepada sumbangan yang lebih tinggi terhadap tingkat keuntungan bank, dimana pihak bank Swasta "XYZ" Cabang Pekanbaru haruslah lebih memperhatikan masalah perluasan jaringan dan sokongan prasarana bank dalam usaha mempertingkatkan kedayasaingannya. Selain itu, kesempurnaan sistem dan prosedur bank juga perlu diberi perhatian. Perkara ini merujuk kepada peningkatan kemudahan dalam proses pembukaan account, penyimpanan dan pengeluaran uang. Di samping itu, kepekaan pihak bank terhadap permintaan pelanggan juga penting dalam hal ini supaya brand loyalty tercipta. Kesan dari pada ini, wujud segolongan pelanggan yang setia kepada bank. Juga, pihak bank Swasta "XYZ" Cabang Pekanbaru boleh cuba meningkatkan keindahan interior dan eksterior bank supaya pelanggan bank dapat menerima pelayanan bank dalam suasana yang menyenangkan. Keadaan ini sudah tentunya boleh menjadi daya tarik pelanggan ke bank tersebut dan kesan akhirnya jumlah keuntungan bank 
akan mengalami pertumbuhan yang menggalakkan.

\section{Daftar Pustaka}

Aaker A. David, 1991, Managing Brand Equity, Capitalizing on The Value of Brand Name, The Press, Mc Millan Inc., New York.

Adrian Payne, 1993, The Assence of Service Marketing, Prentice Hall, New Tork.

Bernard Katz, 1991, Bagaimana Memasarkan Jasa Profesional, Penerjemah Liana Setiono, Cetakan Pertama, IPPM, Penerbit PT. Pustaka Binaman Pressindo, Jakarta.

Berry Leonard L. and Parasuraman A., 1998, Marketing Service, Mc Millan Inc., Englinton Avenue East, New York.

Budi Widjaja Soetjipto, 1994, Tinjauan Masalah: Strategi Manajemen Kualitas Dalam Era Globalisasi, Manajemen \& Usahawan Indonesia, No. $10^{\text {Th }}$ XXIV, Oktober, Jakarta.

Budiman Yas, 1995, Antisipasi Asuransi Nasional Menyongsong Era GATT, Ancmaan dan Peluang, Manajemen \& Usahawan Indonesia, No. 01 Th XXIV, Januari, Jakarta.

Chrysanti dan Soedyono, 1994, Etika Bisnis dan Konsumen, Manajemen \& Usahawan Indonesia, No. 2 Th XXIII, February, Jakarta.

Djaslim Saladin, 1994, Dasar-Dasar Manajemen Pemasaran Bank, CV. Mandar Maju, Bandung.

Fandy Tjiptono, 1997, Prinsip-Prinsip Total Quality Service, Penerbit Andi, Yogyakarta

Penerbit Andi, Yogyakarta..

Manajemen
Kontemporer,
Yan Penerbit Andi,
Yogyakarta

Foster, 1999, Prinsip-Prinsip Pemasaran, Seri Manajemen, No. 50, Erlangga, Jakarta..

Griffin Jill, 1995, Customer Loyalty : How to Earn It, How ti Keep It, Lexington Books, Sinagpore.

Hafid, 1995, Tulisan Utama: Upaya Untuk Meningkatkan Produktivitas dan Kualitas Perusahaan, Manajemen \& Usahawan Indonesia, No. $10^{\text {Th }}$ XXIV, Oktober, Jakarta.

Hermawan Kertajaya, 1995, Kolom: Analisis 3-C, Manajemen \& Usahawan Indonesia, No, 4 Th. XXIII, April.

Husein Umar, 1999, Metodologi Penelitian: Aplikasi Dalam Pemasaran, PT. Gramedia Pustaka Umum, Jakarta

Jennie Siat, 1997, Relationship Marketing, Majalah Swa, No. 03/XXVI/Juli, Jakarta.

Mudrick, Robert G., Render Barry, Russel, Roberta S., 1990, Service Operations Management, Allyn and Bacon.

Murti Sumarni, 1993, Pemasaran Perbankan, Liberty, Yogyakarta.

Philip Kotler, 1991, Manajemen Pemasaran: Analisis, Perencanaan dan Pengendalian, Jilid 2, Terjemahan Jaka Wasara dan Herujadi Purwoko, Edisi Kelima, Erlangga, Jakarta.

Philip Kotler, 1993, Manajemen Pemasaran: Analisis, Perencanaan, 
Implementasi dan Pengendalian, Penerjemah Adi Zakaria Afif, Volume Pertama, Edisi Ketujuh, Lembaga Penerbit FE-UI, Jakarta.

- 1994, Principles of Marketing, Third Edition, Prentice Hall, New Jersey.

Pemasarajemen

Pemasaran: Analisis, Perencanaan, Implementasi dan Kontrol, Jilid 1, Edisi Kesembilan, Erlangga, Jakarta.

Prijono Tjiptoherijanto, 1994, Pemerataan di Sektor Perdagangan, Manajemen \& Usawahan Indonesia, No. 6 Th XXIII, Juni, Jakarta.

Singarimbun, Masri dan Sofian Effendi, 1999, Metode Penelitian Survey, Penerbit LP3ES, Jakarta.

Sudjana, 1992, Metode Statistika, Edisi Kelima, Tarsito, Bandung
Wahana Komputer, 1997, Panduan Lengkap SPSS 6.0 for Windows, Penerbit Andi, Yogyakarta.

Walpole, 1990, Introduction to Statistics, Mc Millan, London.

Widayat dan Amirullah, 2002, Riset Bisnis, Penerbit Graha Ilmu, Yogyakarta.

William J. Stanton, 1994, Fundamental of Marketing, $8^{\text {th }}$ Edition, Mc Graw Hill, Sinngapore.

----------------, 1996, Prinsip Pemasaran, Alih Bahasa Yohanas Lamarto, Jilid 1, Edisi Ketujuh, Erlangga, Jakarta.

Yazid, .1999, Pemasaran Jasa; Konsep dan Implementasi, Edisi Pertama, Ekonosia, Fakultas UII, Ypgtakarta.

Zeithaml, Valarie A and Mary Jo. Bitner, 1996, Services Marketing, The McGraw-Hill Companies, Inc., New Jersey. 